\title{
Hypervolemic-Hemodilution and Hypertension During Temporary Middle Cerebral Artery Occlusion in Rats: The Effect on Blood-Brain Barrier Permeability
}

\author{
Daniel J. Cole, John C. Drummond, Jerry S. Matsumura, Suzzanne Marcantonio \\ and Bonnie I. Chi-Lum
}

\begin{abstract}
The effect of hypervolemic-hemodilution, with and without hypertension, on blood-brain barrier permeability was investigated in rats, after 180 minutes of middle cerebral artery occlusion (MCAo), and 60 minutes of reperfusion. One of the following conditions was maintained during MCAo: 1) Control - hematocrit and blood pressure were not manipulated; 2) Hypervolemic-Hemodilution/Normotension - the hematocrit was decreased to $30 \%$; 3 ) Hypervolemic-Hemodilution/Hypertension - the hematocrit was decreased to $30 \%$ and mean arterial pressure increased by $30 \mathrm{mmHg}$ with phenylphrine. In all groups, Evans Blue was administered, and its concentration determined by spectrophotometric assay. Evans Blue $\left(\mu \mathrm{g} / \mathrm{g}^{-1}\right.$ of brain tissue [mean $\pm \mathrm{SD}$ ]) was greater in the HypervolemicHemodilution/Hypertension group $(71 \pm 20)$ versus the Control $(13 \pm 9)$ and Hypervolemic-Hemodilution/ Normotension $(17 \pm 10)$ groups $(p<0.05)$. No other differences were present. These results support the hypothesis that during MCAo, hypervolemic-hemodilution/hypertensive therapy effects an increase in blood-brain barrier permeability in the early period of reperfusion.
\end{abstract}

RÉSUMÉ: Hémodilution hypervolémique et hypertension pendant l'occlusion temporaire de l'artère cérébrale moyenne chez le rat: effet sur la perméabilité de la barrière hémo-encéphalique Nous avons investigué l'effet de l'hémodilution hypervolémique, avec ou sans hypertension, sur la perméabilité de la barrière hémo-encéphalique chez la rat, 180 minutes après l'occlusion de l'artère cérébrale moyenne (OACM) et une reperfusion de 60 minutes. Une des conditions suivantes a été maintenue pendant l'oACM: 1) l'hématocrite et la pression artérielle de base n'ont pas été modifiés; 2) hémodilution hypervolémique/normotension - l'hématocrite était diminué à 30\%; 3) hémodilution hypervolémique/hypertension - l'hématocrite était diminué à $30 \%$ et la pression artérielle moyenne augmentée de $30 \mathrm{mmHg}$ par le phényléphrine. Dans tous les groupes, nous avons injecté du bleu Evans et nous avons déterminé sa concentration par spectrophotométrie. La concentration de bleu Evans $\left(\mu \mathrm{g}_{-} \mathrm{g}^{-1}\right.$ de tissu cérébral (moyenne $\pm \mathrm{SD}$ ) était plus importante dans le groupe hémodilution hypervolémique/hypertension $(71 \pm 20)$ versus le groupe contrôle $(13 \pm 9)$ et le groupe hémodilution hypervolémique/normotension $(17 \pm 10)(\mathrm{p}<0.05)$. Il n'y avait aucune autre différence entre les groupes. Ces résultats supportent l'hypothèse selon laquelle le traitement de l'hypertension dans l'hémodilution hypervolémique pendant l'oACM cause une augmentation de la perméabilité de la battière hémoencéphalique au début de la reperfusion.

Can. J. Neurol. Sci. 1990; 17: 372-377

Physiologic manipulations such as hemodilution, hypervolemia, and hypertension, which improve cerebral blood flow (CBF), have nonetheless had variable success on outcome following focal cerebral ischemia. ${ }^{1-8}$ One possible explanation for this variability is that in spite of augmenting $\mathrm{CBF}$, these therapies might detrimentally contribute to injury processes that secondarily worsen the original injury (e.g., cerebral edema).9.10 Previous studies in our laboratory have shown that during middle cerebral artery occlusion (MCAo) in rats, hypervolemichemodilution/hypertensive $(\mathrm{H}-\mathrm{H} / \mathrm{HTN})$ therapy effects an increase in $\mathrm{CBF}$ to ischemic brain areas, and a decrease in cerebral injury and brain water content following temporary MCAo, $1,11-13$ Accordingly, it was postulated that a primary mechanism whereby $\mathrm{H}-\mathrm{H} / \mathrm{HTN}$ therapy decreases brain water content is by reducing the cytotoxic component of ischemic cerebral edema. 11,13

In the early period of permanent cerebral ischemia, edema is predominately effected by cytotoxic mechanisms. ${ }^{14.15}$ However, in the event of reperfusion, edema can be influenced by both cytotoxic and vasogenic (blood-brain barrier permeability)

From the Departments of Anesthesiology, Loma Linda University, Loma Linda (D.J.C., J.S.M., S.M., B.I.C.-L.); the Veteran's Administration Medical Center, San Diego (J.C.D.), and the University of California at San Diego, La Jolla, California (J.C.D.)

Received April 25, 1990. Accepted in final form August 8, 1990

Reprint requests to: Daniel J. Cole, Department of Anesthesiology, Loma Linda University, Loma Linda, California 92354, U.S.A. 
properties. ${ }^{14,15}$ Thus, in our model of temporary $\mathrm{MCAo}^{11}$ we considered it possible that $\mathrm{H}-\mathrm{H} / \mathrm{HTN}$ therapy might exert a detrimental effect on blood-brain barrier permeability that was obscured by an overwhelmingly positive effect on cytotoxic edema formation.

There is evidence suggesting that hypertension, per se, may disrupt the blood-brain barrier. ${ }^{16-18}$ The manifestation of bloodbrain barrier disruption, due to hypertensive treatment during a period of temporary focal cerebral ischemia, might be paramount during the early period of reperfusion when the vasculature is suddenly exposed to increases in intraluminal pressure. ${ }^{19}$ Such a concern might pertain to the clinical situation in which thrombolytic therapy is considered. ${ }^{20}$ During a diagnostic delay, therapeutic goals might include minimizing the existing injury without exacerbating secondary injury (e.g., vasogenic edema). The present study was designed to determine if $\mathrm{H}-\mathrm{H} / \mathrm{HTN}$ therapy, employed during temporary MCAo, effects blood-brain barrier permeability in the early period of reperfusion.

\section{Materials and Methods}

The protocol was reviewed and approved by the Animal Research Committee of Loma Linda University under the animal care guidelines of the United States Department of Health and Human Services. Male, Spontaneously Hypertensive Rats (350-400 grams) were anesthetized with isoflurane, orotracheally intubated, and mechanically ventilated with a Harvard Rodent Respirator (Harvard Apparatus Co., Boston, MA). The isoflurane concentration was maintained at $1.44 \%$ end-tidal during the preparatory and study period. The femoral vessels were cannulated for blood pressure monitoring, blood sampling, and fluid and drug administration. Sodium chloride $(0.9 \%)$ was administered at a rate of $4 \mathrm{ml} \cdot \mathrm{kg}^{-1} \cdot$ hour ${ }^{-1}$. Physiologic monitoring included mean arterial pressure (MAP), $\mathrm{pH}, \mathrm{PaCO}_{2} \mathrm{PaO}_{2}$, serum glucose, and hematocrit. Rectal temperature was servo-controlled at $37^{\circ} \mathrm{C}$ with a heating blanket. Physiologic values were recorded every fifteen minutes and reported as an average over the MCAo and reperfusion period.

The left middle cerebral artery was exposed via a small subtemporal craniectomy. Each rat was randomly assigned one of the following treatments which was implemented immediately prior to, and maintained during MCAo:

Control $(\mathbf{n}=\mathbf{8})$. Neither hematocrit, blood volume, nor MAP were manipulated.

Hypervolemic-Hemodilution $(\mathbf{H}-\mathbf{H}, \mathbf{n}=\mathbf{8})$. Five per cent human albumin (Travenol Laboratories, Glendale, CA) was administered to maintain a hematocrit of $29-32 \%$.

H-H/Hypertension (H-H/HTN, $n=8)$. Hypervolemichemodilution was achieved in a fashion identical to the $\mathrm{H}-\mathrm{H}$ group, and MAP increased by $30 \mathrm{mmHg}$ above baseline with an infusion of phenylephrine.

The middle cerebral artery was then occluded with 10-0 monofilament nylon suture in two locations for 180 minutes. The first location was just proximal to the lenticulostriate arterial branch. The second location was distal to the intersection of the middle cerebral artery with the inferior cerebral vein. In this manner, consistent injury to the basal ganglia and cortex has been achieved in previous studies. 11.13 After 180 minutes of MCAo, the sutures were released and a 60 minute period of reperfusion allowed. Hematocrit, blood volume, and MAP were not manipulated during the reperfusion period.

A surgical sham group was prepared by maintaining five rats in a manner identical to the $\mathrm{H}-\mathrm{H} / \mathrm{HTN}$ group (i.e., 180 minutes of hypervolemic-hemodilution and hypertension), with the exception that the suture was passed, but not tightened around the middle cerebral artery (i.e., ischemia was not induced).

Thirty minutes after ligature release, $1 \mathrm{ml} \cdot \mathrm{kg}^{-1}$ body weight of 3\% Evans Blue was injected intravenously and allowed to circulate for 30 minutes. This dose provided for equivalent serum concentrations of Evans Blue between groups, and was totally bound to serum albumin as determined by reacting rat serum with trichloroacetic acid.21 After the 30 minute period of Evans Blue circulation, the animals were euthanized, and the amount and area of Evans Blue was determined in the hemisphere ipsilateral to MCAo by spectrophotometry and image analysis. Briefly described, the descending aorta was crossclamped and Evans Blue was cleared from the vascular space by aortic perfusion of $0.9 \% \mathrm{NaCl}$ at $37^{\circ} \mathrm{C}(100 \mathrm{ml})$. The brains were removed and coronally sectioned $3: 0,5.0$, and $7.0 \mathrm{~mm}$ from the frontal pole (see Figure 1). Each coronal segment was divided into hemispheres and immersed for 72 hours in $100 \%$ Formamide Reagent (Fisher Scientific, Los Angeles, CA) at a ratio of $1 \mathrm{ml} \cdot 100 \mathrm{mg}^{-1}$ of brain tissue. After 72 hours, the optical density of the Evans Blue/formamide diluent was determined using a Hitachi 100-80 Computerized Spectrophotometer (Hitachi Instruments Inc., San Jose, CA) set at an absorbance wave length of $620 \mathrm{~nm}$. The concentration of Evans Blue in each hemisphere

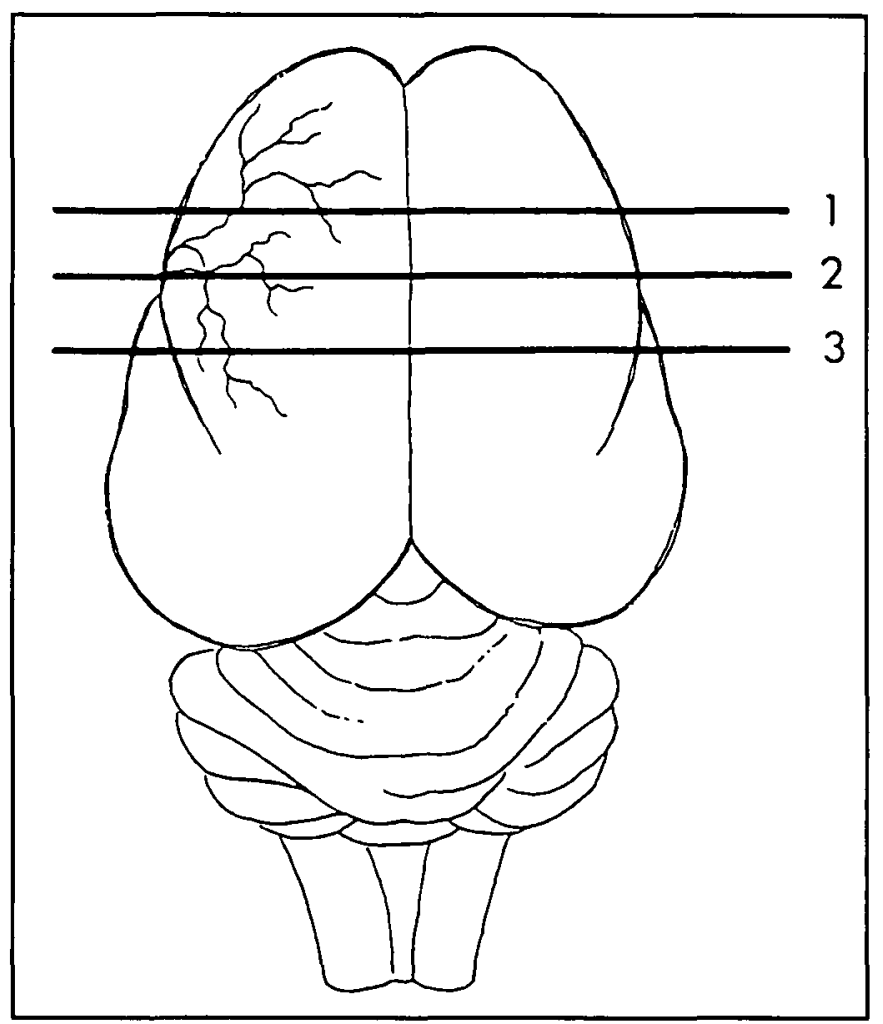

Figure I - Coronal brain sections in which the area of Evans Blue extravasation was deternined. Section I was $3.0 \mathrm{~mm}$ posterior to the frontal pole. Section 2 was $5.0 \mathrm{~mm}$ posterior to the frontal pole. Section 3 was $7.0 \mathrm{~mm}$ posterior to the frontal pole. See tevt for fur. ther explanation. 
was determined by reference to a regression curve derived from Evans Blue/formamide standards. The change in blood-brain barrier permeability due to MCAo was then calculated by subtracting the amount of Evans Blue in the hemisphere contralateral to MCAo from the amount of Evans Blue in the hemisphere ipsilateral to MCAo. ${ }^{22}$

Image analysis of the area of Evans Blue extravasation in brain tissue was determined by taking photographs of each coronal surface (3.0, 5.0 , and $7.0 \mathrm{~mm}$ from the frontal pole) immediately before formamide extraction (Kodak Ektachrome, tungsten 160 ASA). The pictures were analyzed by an independent observer who was blinded to the study protocol, using a Drexel/DUMAS Image Analyzer in order to determine the area of Evans Blue extravasation.

Statistical analysis was performed on the physiologic and Evans Blue data using an analysis of variance, and as appropriate, mean values were compared by t-tests with a Bonferroni correction for multiple comparisons. ${ }^{23}$ All values are reported as mean \pm SD. A $p$ value of less than 0.05 was considered significant.

\section{RESUITS}

During the occlusion period there were no between groups differences in $\mathrm{pH}, \mathrm{PaCO}_{2}, \mathrm{PaO}_{2}$, and serum glucose. There were differences in hematocrit and MAP (see Table 1). The average phenylephrine dose required to maintain a MAP increase of $30 \mathrm{mmHg}$ in the $\mathrm{H}-\mathrm{H} / \mathrm{HTN}$ group was $18 \pm 4 \mu \mathrm{g} \cdot \mathrm{kg}^{-1} \cdot \mathrm{min}^{-1}$. During reperfusion there were no between groups differences in $\mathrm{pH}, \mathrm{PaCO}_{2}, \mathrm{PaO}_{2}$, and MAP (see Table 1). However, during reperfusion there were differences in hematocrit and serum glucose (see Table 1).

The amount of Evans Blue ( $\mu \mathrm{g} \cdot \mathrm{g}^{-1}$ of brain tissue) that crossed the blood-brain barrier in the hemisphere ipsilateral to MCAo was greater in the H-H/HTN group $(71.3 \pm 20.2)$, than in

Table 1: Physiologic Data (mean \pm SD)

$\mathrm{H}-\mathrm{H}$ is the hypervolemic-hemodilution group. $\mathrm{H}-\mathrm{H} / \mathrm{HTN}$ is the group that received both hypervolemic-hemodilution and phenylephrineinduced hypertension.

\begin{tabular}{|c|c|c|c|}
\hline \multicolumn{4}{|c|}{ Occlusion Period } \\
\hline $\mathrm{pH}$ (units) & $7.41 \pm 0.03$ & $7.42 \pm 0.02$ & $7.40 \pm 0.03$ \\
\hline $\mathrm{PaO}_{2}(\mathrm{mmHg})$ & $144 \pm 23$ & $155 \pm 23$ & $149 \pm 17$ \\
\hline $\mathrm{PaCO}_{2}(\mathrm{mmHg})$ & $39.1 \pm 1.6$ & $38.7 \pm 1.3$ & $37.6 \pm 2.3$ \\
\hline Hematocrit (\%) & $44 \pm 3$ & $30 \pm 1^{*}$ & $30 \pm 1^{*}$ \\
\hline MAP $(\mathrm{mmHg})$ & $132 \pm 3$ & $124 \pm 6^{*}$ & $161 \pm 5 \dagger$ \\
\hline Glucose $\left(\mathrm{mg} \cdot \mathrm{dl}^{-1}\right)$ & $116 \pm 26$ & $114 \pm 17$ & $123 \pm 24$ \\
\hline \multicolumn{4}{|c|}{ Reperfusion Period } \\
\hline & Control & H-H & H.H/HTN \\
\hline $\mathrm{pH}$ (units) & $7.39 \pm 0.03$ & $7.42 \pm 0.04$ & $7.39 \pm 0.04$ \\
\hline $\mathrm{PaO}_{2}(\mathrm{mmHg})$ & $146 \pm 29$ & $140 \pm 18$ & $137 \pm 30$ \\
\hline $\mathrm{PaCO}_{2}(\mathrm{mmHg})$ & $38.2 \pm 2.5$ & $37.0 \pm 2.2$ & $36.6 \pm 2.3$ \\
\hline Hematocrit (\%) & $40 \pm 3$ & $29 \pm 1^{*}$ & $30 \pm 3 *$ \\
\hline $\mathrm{MAP}(\mathrm{mmHg})$ & $120 \pm 14$ & $123 \pm 10$ & $121 \pm 5$ \\
\hline Glucose $\left(\mathrm{mg} \cdot \mathrm{dl}^{-1}\right)$ & $119 \pm 17$ & $117 \pm 10$ & $86 \pm 12 \dagger$ \\
\hline
\end{tabular}

$* p<0.05$ versus the Control group.

$\dagger p<0.05$ versus the Control and $\mathrm{H}-\mathrm{H}$ groups. the $\mathrm{H}-\mathrm{H}(16.8 \pm 9.8)$ and Control $(13.1 \pm 9.4$ groups (see Table 2). There was no difference between the $\mathrm{H}-\mathrm{H}$ and Control groups.

Table 2: The Amount of Evans Blue That Crossed the Blood-Brain Barrier in the Cerebral Hemisphere Ipsilateral to MCAo $\left(\mu \mathrm{g} \cdot \mathrm{g}^{\cdot 1}\right.$ of Brain Tissue [mean \pm SD]). See Table 1 for group abbreviations.

\begin{tabular}{lc}
\hline Group & Evans Blue Concentration \\
\hline Control & $13.1 \pm 9.4$ \\
H-H & $16.8 \pm 9.8$ \\
H-H/HTN & $71.3 \pm 20.2^{*}$ \\
\hline
\end{tabular}

${ }^{*} \mathrm{p}<0.05$ versus the Control and $\mathrm{H}-\mathrm{H}$ groups.

The area of Evans Blue extravasation in the hemisphere ipsilateral to MCAo is listed in Table 3 and illustrated in Figure 2. In sections 1 and 2 , the area of extravasation was greater in the $\mathrm{H}-\mathrm{H} / \mathrm{HTN}$ group, as compared to the Control and $\mathrm{H}-\mathrm{H}$ groups. In section 3 the area of extravasation was greater in the $\mathrm{H}$ $\mathrm{H} / \mathrm{HTN}$ group, as compared to the Control group. There was no significant difference between the $\mathrm{H}-\mathrm{H}$ and Control groups. Evans Blue was not visible in the hemisphere contralateral to MCAo.

For the five animals in which the 10-0 monofilament suture was passed, but not tightened around the middle cerebral artery, the average Evans Blue concentration in the hemisphere ipsilateral to middle cerebral artery manipulation was $2.9 \pm 0.7 \mu \mathrm{g} \cdot \mathrm{g}^{-1}$ of brain tissue.

\section{Discussion}

The results of this study indicate that hypervolemic-hemodilution did not alter blood-brain barrier permeability to albumin following temporary MCAo. However, when hypervolemichemodilution was combined with a $30 \mathrm{mmHg}$ increase in MAP, blood-brain barrier permeability to albumin and its spread

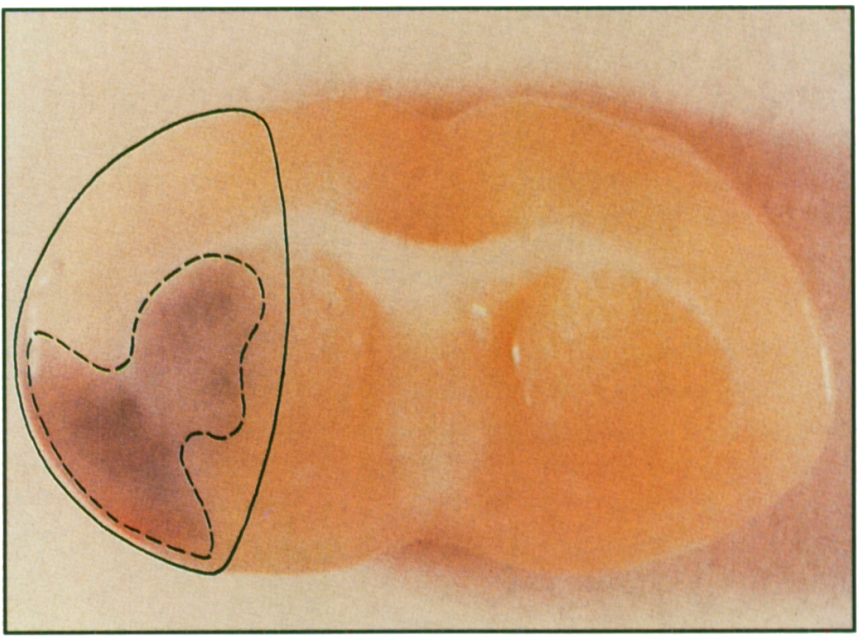

Figure 2 - An example of Evans Blue extravasation in the H-HIHTN group. The solid line delineates the area of consistent ischemia that was evaluated for absolute $C B F$. Although ischemia was not evaluated, in previous studies this area is $\approx 35-40 \%$ of the hemisphere, with a variance $(S D)$ of $9-12 \% .11 .26$ The dashed line defines the area of Evans Blue extravasation. In general, this area was confined to the cerebral cortex. However, for three animals in the H-HIHTN group Evans Blue extravasated into the sub-cortex. 
Table 3: The Percentage of the Hemisphere Ipsilateral to the Occluded Middle Cerebral Artery with Evans Blue Extravasation (mean $\pm \mathrm{SD}$ ) in Coronal Sections 3.0, 5.0, and $7.0 \mathrm{~mm}$ Posterior to the Frontal Pole. See Figure 1 for precise location of coronal sections, Figure 2 for example, and Table 1 for group abbreviations.

\begin{tabular}{lccc} 
& Control & H-H & H-H/HTN \\
\hline Section 1 & $8.7 \pm 2.6$ & $7.5 \pm 2.6$ & $14.5 \pm 5.6^{*}$ \\
Section 2 & $7.3 \pm 2.6$ & $8.5 \pm 2.6$ & $14.3 \pm 5.1^{*}$ \\
Section 3 & $4.2 \pm 2.3$ & $5.9 \pm 2.1$ & $6.8 \pm 2.2 \dagger$ \\
\hline
\end{tabular}

$* \mathrm{p}<0.05$ versus the Control and $\mathrm{H}-\mathrm{H}$ groups.

$\dagger p<0.05$ versus the Control group.

increased. This is consistent with a hypothesis that although $\mathrm{H}-\mathrm{H} / \mathrm{HTN}$ therapy augments CBF, and decreases brain injury and cytotoxic cerebral edema; $1,11-13$ such therapy conveys a risk of worsening vasogenic edema which might detrimentally effect ischemic injury. ${ }^{15}$

Notable physiologic differences include an $8 \mathrm{mmHg}$ reduction in MAP during MCAo in the $\mathrm{H}-\mathrm{H}$ group compared to the Control group. In addition, there was a decrease in serum glucose for the $\mathrm{H}-\mathrm{H} / \mathrm{HTN}$ group during reperfusion. We have observed this effect in a previous study, $"$ and postulate it to be due to a rebound phenomenon mediated at pancreatic $\alpha$-adrenergic receptors when discontinuing the $\alpha$-adrenergic agonist phenylephrine. ${ }^{24}$ If this difference $\left(\approx 30 \mathrm{mg} \cdot \mathrm{dl}^{-1}\right)$ had any effect on blood-brain barrier function, it is likely to have improved the ischemic state in the $\mathrm{H}-\mathrm{H} / \mathrm{HTN}$ group, and underestimated the detrimental effect of $\mathrm{H}-\mathrm{H} / \mathrm{HTN}$ therapy on blood-brain barrier permeability. 25

In the present study blood-brain barrier permeability was assessed by the indicator dye Evans Blue (molecular weight-961 daltons), which binds to albumin (molecular weight $\approx 68,500$ daltons) and does not normally cross the blood-brain barrier in appreciable amounts. ${ }^{21,22}$ We assessed cerebral Evans Blue by two methods that address unique aspects of vasogenic edema. Spectrophotometry was used as a direct assessment of bloodbrain barrier permeability to the Evans Blue:albumin complex, and an indirect indicator of vasogenic edema formation. ${ }^{15}$ In addition, the area of Evans Blue staining was determined by image analysis, which is suggestive of the spread of vasogenic edema and secondary injury. 15 One critique of this methodology is that a major component of Evans Blue in the hemisphere ipsilateral to MCAo was intravascular, and not intraparenchymal. This seems unlikely for the following reasons: 1) Evans Blue in the hemisphere contralateral to MCAo and in sham animals was $\approx 2-3 \mu \mathrm{g} \cdot \mathrm{g}^{-1}$ of brain tissue, 2) in pilot studies, $100 \mathrm{ml}$ of saline was more than twice the volume necessary to totally wash out Evans Blue from the cerebral venous effluent (measured by spectrophotometry), and 3) after identical perfusion fixation, light microscopy has revealed minimal areas in the hemisphere ipsilateral to MCAo with intravascular blood. 26

Simplistically, the diffusion of a substance across a membrane depends on the concentration gradient, a membrane permeability factor, and membrane area. One characteristic of cerebral ischemia is a disintegration of the microvasculature, resulting in blood-brain barrier permeability changes that correlate with the magnitude of ischemic injury. $27-29$ Previous studies with similar models of focal cerebral ischemia in our laboratory have consistently demonstrated the ability of hypertension to decrease ischemic injury. $11-13$ As there were commensurate serum concentrations of Evans Blue in the three groups, it appears that the Evans Blue increase for the $\mathrm{H}-\mathrm{H} / \mathrm{HTN}$ group was a function of a change in membrane permeability effected by combined hypervolemic-hemodilution/hypertensive therapy. It must be acknowledged that this is speculative as membrane permeability was not directly measured.

We were surprised that a treatment $(\mathrm{H}-\mathrm{H} / \mathrm{HTN})$ which has been shown to reduce ischemic injury, 11.13 aggravated bloodbrain barrier leak to albumin. Furthermore, we did not expect that $\mathrm{H}-\mathrm{H} / \mathrm{HTN}$ therapy during a three hour period of vascular occlusion (when the blood-brain barrier is intact to serum albu$\min ^{14}$ ) would have an appreciable affect on blood-brain barrier permeability to Evans Blue during a subsequent period of normotensive reperfusion. We consider the following hypotheses plausible explanations for the discrepancy between the previous reports of reduced area of ischemic injury achieved by $\mathrm{H}-\mathrm{H} / \mathrm{HTN}$ therapy, 11.13 and the increase in Evans Blue leak reported in the present study.

The first hypothesis is that a reduction in Evans Blue leak due to decrease in area of blood-brain barrier injury was minor compared to the increase effected by $\mathrm{H}-\mathrm{H} / \mathrm{HTN}$ therapy in the remaining area of injury. In a variety of methodological settings, hypertension has resulted in blood-brain barrier disruption, presumably via increased intraluminal hydrostatic pressure. $16-18,30-40$ If blood-brain barrier disruption does occur due to hydrostatic pressure increases induced during MCAo, it might be maximally manifested during reperfusion, when the blood-brain barrier is prone to permeability changes. ${ }^{19}$ The second and related hypothesis, is that phenylephrine might exert similar intraluminal hydrostatic pressure increases in the arterial and venular beds. The following exaggerated example portrays such an event. All other factors being equal, if an apparent $30 \mathrm{mmHg}$ increase in systemic MAP effects a $30 \mathrm{mmHg}$ increase in arterial and venular intraluminal hydrostatic pressure, no net increase in CBF or, decrease in tissue and vascular injury should occur. However, there could be an increase in blood-brain barrier permeability due to the increase in intraluminal hydrostatic pressure. There is evidence in support of this theory, 16-18,41, 42 although the relative contribution by phenylephrine to each vascular bed is not known. Accordingly, this hypothesis remains highly speculative. The third hypothesis involves the direct effect adrenergic agents might have on vascular permeability. ${ }^{38,4.3}$ It has been demonstrated that $\alpha$-adrenergic agents exert an effect on cerebral vascular permeability via a central noradrenergic regulating system. However, the extent to which this property might have been operative in the present study is not known.

With the evolution of thrombolytic stroke therapy, and consequent early reperfusion of ischemic brain; the entry of serum proteins into brain parenchyma, the accompanying vasogenic edema, and the detrimental effect edema has on ischemic injury 15 may become of greater clinical importance. Although thrombolytic therapy has demonstrated an ability to ameliorate neurologic injury following focal cerebral ischemia, ${ }^{20}$ there is evidence to suggest that such therapy might convey a risk of ischemic brain edema. ${ }^{20.44}$ If thrombolytic therapy proves efficacious for human stroke, the clinician may have to care for patients during a diagnostic interval prior to treatment and reperfusion. Manipulation of hemorheology and perfusion pressure during this time may favorably affect primary injury by increas- 
ing collateral flow through anastomotic channels, or via a redistribution of flow to pressure passive vascular areas. $1,4,7,11,13$ Notwithstanding, during the acute phase of reperfusion, Kuroiwa et al, 19 have proposed that a "hemodynamic leak" of the blood-brain barrier occurs, which is associated with the sudden onset of intraluminal pressure and hyperemic CBF. It may be that there is a detrimental effect of $\mathrm{H}-\mathrm{H} / \mathrm{HTN}$ therapy on this "hemodynamic leak" which might influence therapeutic choices prior to the institution of thrombolysis. We acknowledge that the present study only suggests this possibility. It provides no insight into the question of whether the negative effects of $\mathrm{H}$ $\mathrm{H} / \mathrm{HTN}$ therapy outweigh the positive effects.

In summary, we evaluated the effect of hypervolemichemodilution and hypertension on blood-brain barrier permeability to Evans Blue following temporary MCAo. We observed an increase in both blood-brain barrier permeability to Evans Blue, and the area of Evans Blue accumulation in the brain by combined H-H/HTN therapy. These results support the hypothesis that although $\mathrm{H}-\mathrm{H} / \mathrm{HTN}$ therapy has demonstrated an ability to increase $\mathrm{CBF}$ and decrease primary brain injury in previous studies; $1,11-13$ such therapy may also convey a risk of worsening vasogenic edema during the period of reperfusion.

\section{ACKNOWLEDGEMENTS}

The authors gratefully acknowledge the technical assistance of Terrill Osborne; and Jackie Breyer in the preparation of this manuscript. This work was supported in part by a Research Starter Grant from the American Society of Anesthesiologists.

\section{REFERENCES}

I. Drummond JC, Oh Y-S, Cole DJ, et al. Phenylephrine-induced hypertension reduces ischemia following middle cerebral artery occlusion in rats. Stroke 1989; 20: 1538-1544.

2. Italian Acute Stroke Study Group. Haemodilution in acute stroke: results of the Italian haemodilution trial. Lancet 1988; 8581: 318-321.

3. Scandinavian Stroke Study Group. Multicenter trial of hemodilution in acute ischemic stroke. Stroke 1988; 19: 464-471.

4. Symon L, Branston NM, Strong AJ. Autoregulation in acute focal ischemia. An experimental study. Stroke 1976; 7: 547-554.

5. The Hemodilution in Stroke Study Group. Hypervolemic hemodilution treatment of acute stroke. Stroke 1989; 20: 317-323.

6. Tu YK, Heros RC, Karacostas D, et al. Isovolemic hemodilution in experimental focal cerebral ischemia - Part 2: effect on regional cerebral blood flow and size of infarction. J Neurosurg 1988; 69: 82-91.

7. Wise G, Sutter R, Burkholder J. The treatment of brain ischemia with vasopressor drugs. Stroke 1972; 3: 135-140.

8. Wood JH, Simeone FA. Fink EA, et al. Hypervolemic hemodilution in experimental focal cerebral ischemia. J Neurosurg 1983; 59: 500-509.

9. Heros RC, Korosue K. Hemodilution for cerebral ischemia. Stroke 1989; 20: 423-427.

10. Sokrab T-EO, Johansson BB, Kalimo H, et al. A transient hypertensive opening of the blood-brain barrier can lead to brain damage. Acta Neuropathol (Berl) 1988; 75: 557-565.

11. Cole DJ, Drummond JC, Osborne TN, et al. Hypertension and hemodilution during cerebral ischemia reduce brain injury and edema. Am J Physiol (in press).

12. Cole DJ, Drummond JC, Shapiro HM, et al. The effect of hypervolemic-hemodilution with and without induced hypertension on cerebral blood flow following middle cerebral artery occlusion in rats anesthetized with isoflurane. Anesthesiology 1989; 71: $580-585$.
13. Drummond JC, Oh Y-S, Cole DJ. Does phenylephrine-induced hypertension during focal cerebral ischemia aggravate brain edema? Anesthesiology 1989; 71: A567.

14. Gotoh O, Asano T, Koide T, et al. Ischemic brain edema following occlusion of the middle cerebral artery in the rat. I: The time courses of the brain water, sodium and potassium contents and blood-brain barrier permeability to $125 \mathrm{I}$-albumin. Stroke 1985; 16: 101-109.

15. Klatzo I. Brain oedema following brain ischemia and the influence of therapy. Br J Anaesth 1985; 57: 18-22.

16. Fredriksson K, Auer RN, Kalimo H, et al. Cerebral microangiopathy in stroke-prone spontaneously hypertensive rats. An immunohistochemical and ultrastructural study. Acta Neuropathol (Berl) 1988; 75: 241-252.

17. Mayhan WG, Heistad DD. Role of veins and cerebral venous pressure in disruption of the blood-brain barrier. Circulation Research 1986; 59: 216-220.

18. Ulrich K, Kuschinsky W. In vivo effects of alpha-adrenoceptor agonists and antagonists on pial veins of cats. Stroke 1985; 16 : 880-884.

19. Kuroiwa $\mathrm{T}$, Ting $\mathrm{P}$, Martinez $\mathrm{H}$, et al. The biphasic opening of the blood-brain barrier to proteins following temporary middle cerebral artery occlusion. Acta Neuropathol (Berl) 1985; 68: 122-129.

20. Del Zoppo GJ. Thrombolytic therapy in cerebrovascular disease. Stroke 1988; 19: 1174-1179.

21. Clasen RA, Pandolfi S. Vital staining, serum albumin and the bloodbrain barrier. J Neuropathol Exp Neurol 1970; 29: 266-284.

22. Durward QJ, Del Maestra FD, Amacher AL, et al. The influence of systemic arterial pressure and intracranial pressure on the development of cerebral vasogenic edema. J Neurosurg 1983; 59: 803-809.

23. Wilkinson L. Multivariate general linear hypothesis. In: SYSTAT: The System for Statistics. Evanston, IL: SYSTAT, Inc. 1987; 2230 .

24. Weiner N, Taylor P. Drugs acting at synaptic and neuroeffector junction sites. In: Gilman AG, Goodman LS, Rall TW, Murad R., eds. Goodman and Gilman's Pharmacologic Basis of Therapeutics, 6th Edition. New York: Macmillan 1985; 60-99.

25. Helgason CM. Blood glucose and stroke. Stroke 1988; 19: 10491053.

26. Cole DJ, Drummond JC, Ruta TS, et al. Effect of hemodilution and hypertension on cerebral hemorrhage following temporary middle cerebral artery occlusion in rats. Stroke (in press).

27. Arai H, Suzuki M, Yoshimoto T, et al. Early permeability change of macromolecules after transient global ischemia. In: Inaga $\mathrm{Y}$, Klatzo I, Spatz M, eds. Brain Edema. New York: Springer 1985; 149-154.

28. Klatzo I. Pathophysiologic aspects of cerebral ischemia. In: Tower DB, ed. The Nervous System. The Basic Neurosciences, vol 1. New York: Raven Press 1975; 313-322.

29. Nakayama H, Dietrich WD, Watson BD, et al. Photothrombotic occlusion of rat middle cerebral artery: histopathological and hemodynamic sequelae of acute recanalization. J Cereb Blood Flow Metab 1988; 8: 357-366.

30. Auer $\mathrm{L}$. The role of cerebral perfusion pressure as origin of brain edema in acute arterial hypertension. Eur Neurol 1977; 15: 153156.

31. Bell BA, Symon L, Branston NM. CBF and time thresholds for the formation of ischemic cerebral edema and effect of reperfusion in baboons. J Neurosurg 1985; 62: 31.41 .

32. Hansson $\mathrm{H}$, Johansson $\mathrm{BB}$, Blomstrand $\mathrm{C}$. Ultrastructural studies on cerebrovascular permeability in acute hypertension. Acta Neuropathol 1975; 32: 187-198.

33. Kogure K, Busto R, Scheinberg $P$. The role of hydrostatic pressure in ischemic brain edema. Ann Neurol 1981; 9: 273-282.

34. Mayhan WG, Heistad DD. Permeability of blood-brain barrier to various sized molecules. Am J Physiol 1985; 248: H712-H718.

35. Nag S, Robertson DM, Dinsdale HB. Cerebral cortical changes in acute experimental hypertension. An ultrastructural study. Lab Invest 1977; 36: 150-161. 
36. Nag S, Robertson DM, Dinsdale HB. Quantitative estimate of pinocytosis in experimental acute hypertension. Acta Neuropathol 1979; 46: 107-116.

37. Olsen $F$. Increased permeability for plasma components of the cerebral vessels during acute angiotensin hypertension in rats. Acta Pathol Microbiol Scand Sect A 1977; 85: 572-576.

38. Raichle ME, Hartman BK, Eichling JO, et al. Central noradrenergic regulation of cerebral blood flow and vascular permeability. Proc Nat Acad Sci USA 1975; 72: 3726-3730.

39. Shigeno T, Teasdale GM, McCulloch J, et al. Recirculation model following MCA occlusion in rats. Cerebral blood flow, cerebrovascular permeability, and brain edema. J Neurosurg 1985; 63: 272-277.

40. Westergaard E, van Deurs EB, Brondsted HE. Increased vesicular transfer of exogenous peroxidase across cerebral endothelium evoked by acute hypertension. Acta Neuropathol 1977; 37: 141152.

41. Chikovani O, Corkill G, McLeish I, et al. Effect on canine cerebral blood flow of two common pressor agents during prolonged halothane anesthesia. Surg Neurol 1978; 9: 211-213.

42. Waltz AG. Effect of blood pressure on blood flow in ischemic and in nonischemic cerebral cortex. Neurology 1968; 18: 613-621.

43. Weinand ME. Neuropharmacologic control of cerebral capillary. permeability: current implications for therapy of vasogenic brain edema. Medical Hypotheses 1988; 26: 51-53.

44. Koudstaal PJ, Stibbe J, Vermeulen M. Fatal ischaemic brain oedema after early thrombolysis with tissue plasminogen activator in acute stroke. Brit Med J 1988; 297: 1571-1574. 